\title{
Surgical treatment of acyanotic double-outlet right ventricle
}

\author{
MARIAN I. IONESCU, OLIVE SCOTT, AND \\ GEOFFREY H. WOOLER
}

From the Department of Thoracic Surgery and Cardiology, Leeds General Infirmary and Leeds University

Two cases of double-outlet right ventricle in which surgical correction was successful are described. The diagnosis of this lesion should always be suspected in apparently large ventricular septal defects with pulmonary hypertension at systemic level, and further investigation by double catheterization or by angiography should be carried out. The catheterization data do not give accurate measurements of the pulmonary and systemic flows and resistances and are of no help in forecasting the results of surgical treatment.

The rare entity called double-outlet right ventricle (Witham, 1957), in which both great vessels arise from the right ventricle (Edwards, 1960), has been recognized in one or other of its various forms since the last century (Rokitansky, 1875).

During the past 30 years it has been better understood and the detailed pathology has been accurately described (Abbott, 1936 ; Ingham and Willius, 1938 ; Saphir and Lev, 1941 ; Witham, 1957). Recently the lesion has been diagnosed during life (Neufeld, DuShane, Wood, Kirklin, and Edwards, 1961 ; Neufeld, Lucas, Lester, Adams, Anderson, and Edwards, 1962 ; Morgan, Pitman, Goodwin, Steiner, and Hollman, 1962 ; Hollman, personal communication), and we know of about 12 patients who have been treated successfully by surgery (McGoon, 1961 ; Redo, Engle, Holswade, and Goldberg, 1963 ; Kirklin, Harp, and McGoon, 1964).

Basically, the malformation is one in which both great vessels arise from the right ventricle, and the only communication with the left ventricle is through a ventricular septal defect.

Witham (1957) divided this malformation into three groups and called them: (1) true persistent truncus arteriosus arising wholly from the right ventricle; (2) the 'Eisenmenger type' with aortic hypoplasia, coarctation, or atresia, with or without atresia of the mitral valve; and (3) the 'Fallot type' with pulmonary hypoplasia, stenosis, or atresia.

The Fallot and Eisenmenger types are better known under the name of double-outlet right ventricle with or without pulmonary stenosis.

The cases without pulmonary stenosis were further separated anatomically by Neufeld and his associates $(1961,1962)$ into two types on the basis of the position of the ventricular septal defect.

According to the anatomical classification of these authors, type 1 is characterized by a ventricular septal defect situated below the crista supraventricularis. In the classical form of this malformation the continuity between the aortic $\overrightarrow{\vec{\partial}}$ valve and the aortic cusp of the mitral valve is altered either by complete separation of valvular tissue or by an unusually long anterior mitral 3 leaflet. The aorta does not arise from its normal position, i.e., inferior, posterior, and to the left of $\frac{\rho}{3}$ the main pulmonary artery ; instead it originates entirely from the right ventricle and extends vertically upwards and parallel to the pulmonary artery. The aortic root lies to the right of the pulmonary artery, being in a more anterior $N$ position than usual. The aortic valve is higher $N$ than normal and at about the same horizontal $N$ body plane as the pulmonary valve. The aortic ${ }^{\omega}$ orifice thus lies entirely to the right of the ventricular septal defect.

Type 2, of which there are two varieties, is $\Phi_{\infty}$ characterized by the presence of a large ventricular ${ }_{-}^{+}$ septal defect which lies above the crista supra- $\frac{0}{0}$ ventricularis and just below the origin of the great $\stackrel{\mathbb{\Phi}}{\mathbb{D}}$ vessels with the aorta arising entirely from the $\frac{?}{\mathbb{D}}$ right ventricle. In type $2 a$, which is synonymous $\varrho$ with the Taussig Bing complex, the ventricularo septal defect lies below the pulmonary valve. In 
type $2 b$ the ventricular septal defect is closely related not only to the pulmonary valve but also to the transposed aortic valve.

This paper deals only with the acyanotic variety of type 1 double-outlet right ventricle. All cases with desaturated systemic blood, whether this be due to the anatomical malformation itself, as in patients with associated pulmonary stenosis, or to the position of the ventricular septal defect, as in type 2 of Neufeld's classification, or to the reversal of the shunt, which occurs in severe pulmonary vascular disease, are excluded.

Of the cases of double-outlet right ventricle without pulmonary stenosis only the acyanotic ones are at the present time amenable to surgical repair.

We present two patients with type 1 doubleoutlet right ventricle treated surgically in whom a correct pre-operative diagnosis was lacking. The diagnostic difficulties are discussed and the technique of surgical repair through the right atrium is described.

\section{CASE REPORTS}

CASE 1 A 6-year-old girl with known congenital heart disease was first referred to the General Infirmary at Leeds in December 1960 with dyspnoea on exertion. On examination the child was thin but active and alert. No cyanosis was noted. The heart was moderately over-active and the second sound in the pulmonary area was narrowly split and increased in intensity. A grade 4/6 harsh systolic murmur was audible in the left second, third, and fourth intercostal spaces. A grade 3 diastolic murmur was also noted at the apex.

The chest radiograph (Fig. 1) showed an enlarged heart, especially the right atrium and ventricle, and a very large pulmonary artery with considerable increase in the pulmonary vascular markings. The electrocardiogram revealed sinus rhythm $(120 / \mathrm{min}$.), a mean QRS axis at about $+170^{\circ}$, right ventricular hypertrophy, and slight left ventricular hypertrophy. The clinical impression was that of a ventricular septal defect with pulmonary hypertension and left-to-right shunt.

\section{T A B L E I}

CASE 1. CATHETERIZATION DATA, 13 DECEMBER 1960

\begin{tabular}{l|l}
\hline \multicolumn{1}{c|}{ Oxygen Saturation (\%) } & \multicolumn{1}{c}{ Pressure (mm. Hg) } \\
\hline $\begin{array}{l}\text { Inferior vena cava } 71 \\
\text { Superior vena cava } 70\end{array}$ & $\begin{array}{l}\text { Radial artery } 2 /-4 \\
\text { Right ventricle } 80 / 0 \\
\text { Radial artery 68 } \\
\text { Right ventricle inflow tract } 76 \\
\text { Right ventricle outflow tract } 86\end{array}$ \\
$\begin{array}{l}\text { Aorta } 90 / 60 \\
\text { Aorta through patent ductus } \\
\text { arteriosus } 94\end{array}$ & \\
\hline
\end{tabular}

Cardiac catheterization was performed and the data are summarized in Table I.

A diagnosis of patent ductus arteriosus with ventricular septal defect and pulmonary hypertension was made. It was considered at that time that a twostage operation would be preferable.

Surgical closure of the ductus was performed in March 1961. At operation it was noted that the aorta proximal to the ductus was extremely small, $0.75 \mathrm{~cm}$. in diameter, the ductus itself and the descending aorta being more than $1 \mathrm{~cm}$. across. There was virtually no thrill palpable over the pulmonary artery prior to ligation of the ductus.

Subsequently it became apparent that the operation had resulted in no symptomatic improvement. The child was therefore readmitted in November 1962. On clinical examination there was bulging of the precordium, a short systolic thrill over the left sternal border, a grade $3 / 6$ holosystolic murmur audible in the third and fourth left interspaces, and a grade 3 diastolic murmur at the apex. The chest radiograph (Fig. 2) showed that the heart was a little smaller in relation to the size of the thorax than in 1960 , with no obvious change in the main pulmonary vessels. The electrocardiogram was unchanged. Cardiac catheterization was again performed and the results, summarized in Table II, confirmed the diagnosis of ventricular septal defect with pulmonary hypertension and large left-to-right shunt.

\section{T A B L E I I}

CASE 1. CATHETERIZATION DATA, 7 SEPTEMBER 1962

\begin{tabular}{l|l}
\hline Oxygen Saturation (\%) & Pressure (mm. Hg) \\
\hline $\begin{array}{l}\text { Superior vena cava 64.1 } \\
\text { Radial artery 68.6 } \\
\text { Right ventricle 76 }\end{array}$ & $\begin{array}{l}\text { Right ventricle 80/0 } \\
\text { Pulmonary artery 80/40 }\end{array}$ \\
\hline
\end{tabular}

Indicator dilution curves showed patterns consistent with a left-toright shunt at ventricular level of considerable magnitude and excluded right-to-left shunt.

Closure of the ventricular septal defect was considered hazardous at that time and therefore was not undertaken until 1966. In November 1966 the heart was exposed through a median sternotomy, and after opening the pericardium it became apparent that the aortic root was transposed to the right of the pulmonary artery and on the same horizontal plane. The diameter of the pulmonary artery was at least three times that of the aorta, which was much smaller than normal. A double-outlet right ventricle was suspected from these findings.

Using heart-lung bypass, the right ventricular cavity was exposed through an incision in the right atrium after detaching the septal leaflet of the tricuspid valve from the annulus. An excellent view was thereby obtained and the diagnosis of double-outlet right ventricle type 1 was confirmed. The aortic valve was situated to the right and on the same coronal plane as the pulmonary valve. The ventricular septal defect, 


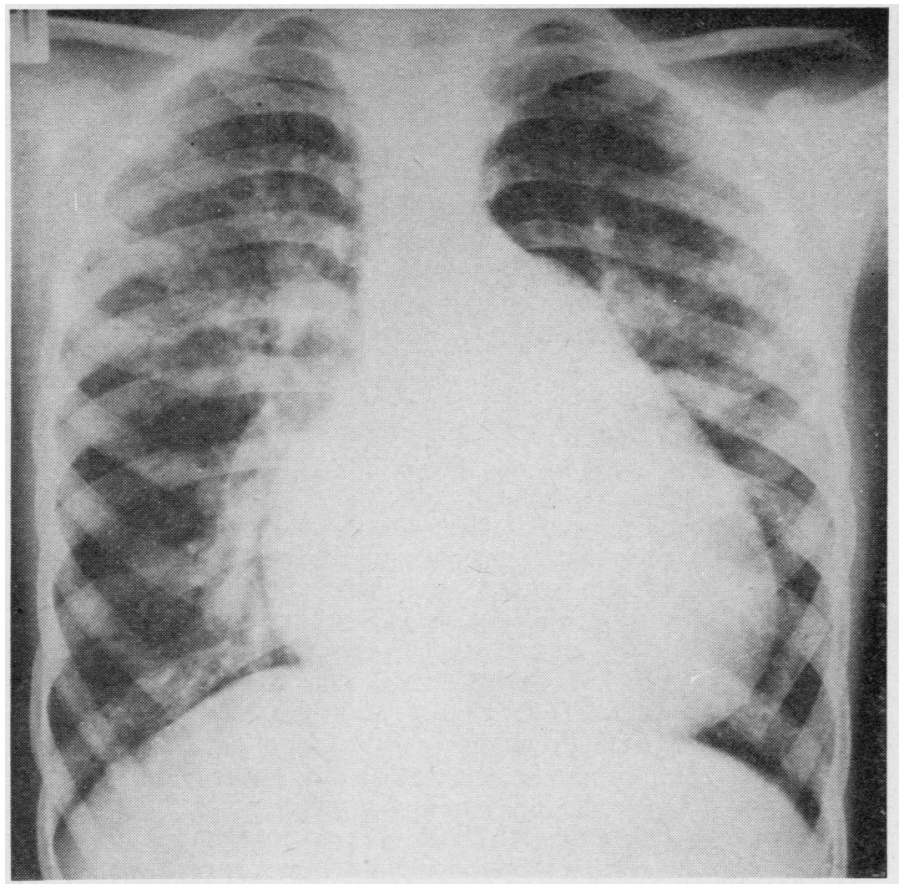

FIG. 1. Case 1. Chest radiograph December 1960. Shows an enlarged Keart, especially the right ventricle and $\overrightarrow{\vec{\omega}}$ right atrium, and a very large pul monary artery. There is considerable increase in the pulmonary vascular. markings.

FIG. 2. Case 1. Chest radiograph November 1962. The heart is a little smaller in relation to the size of the thorax in comparison with Figure 1. There is no obvious change in the main puimonary vessels.

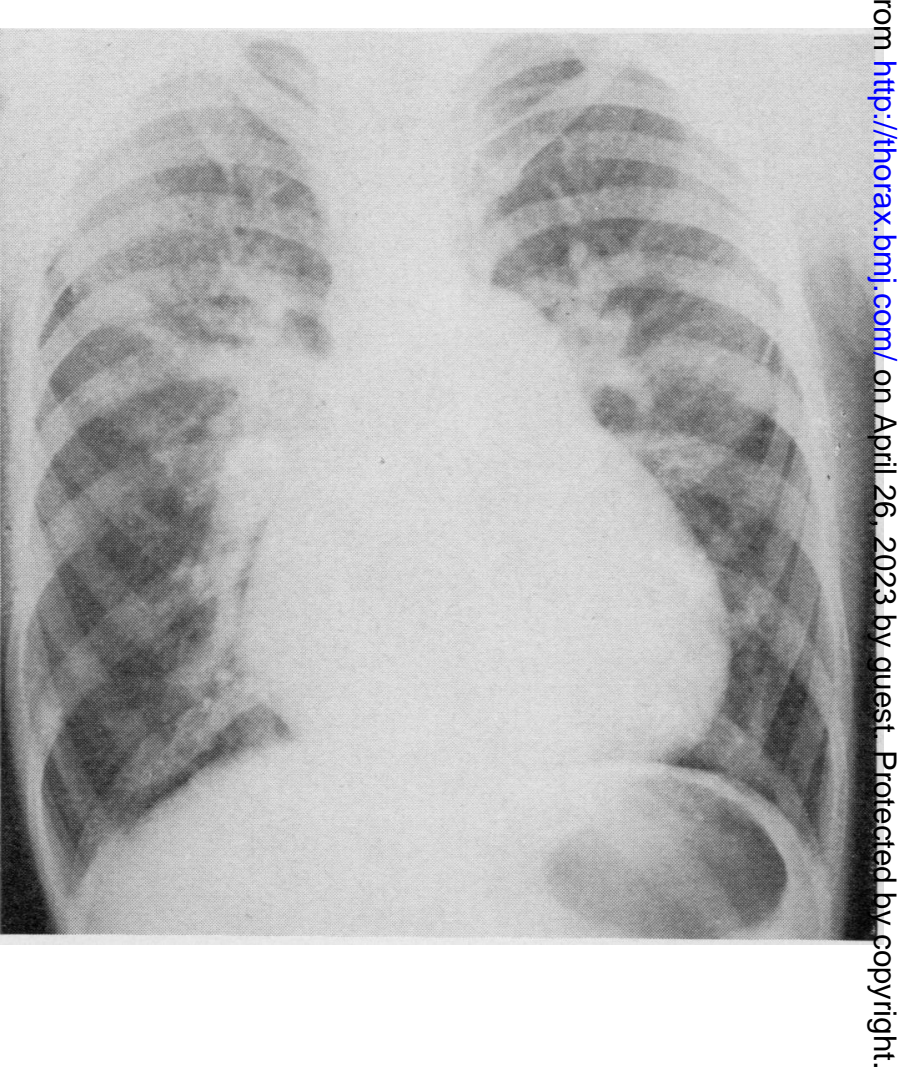




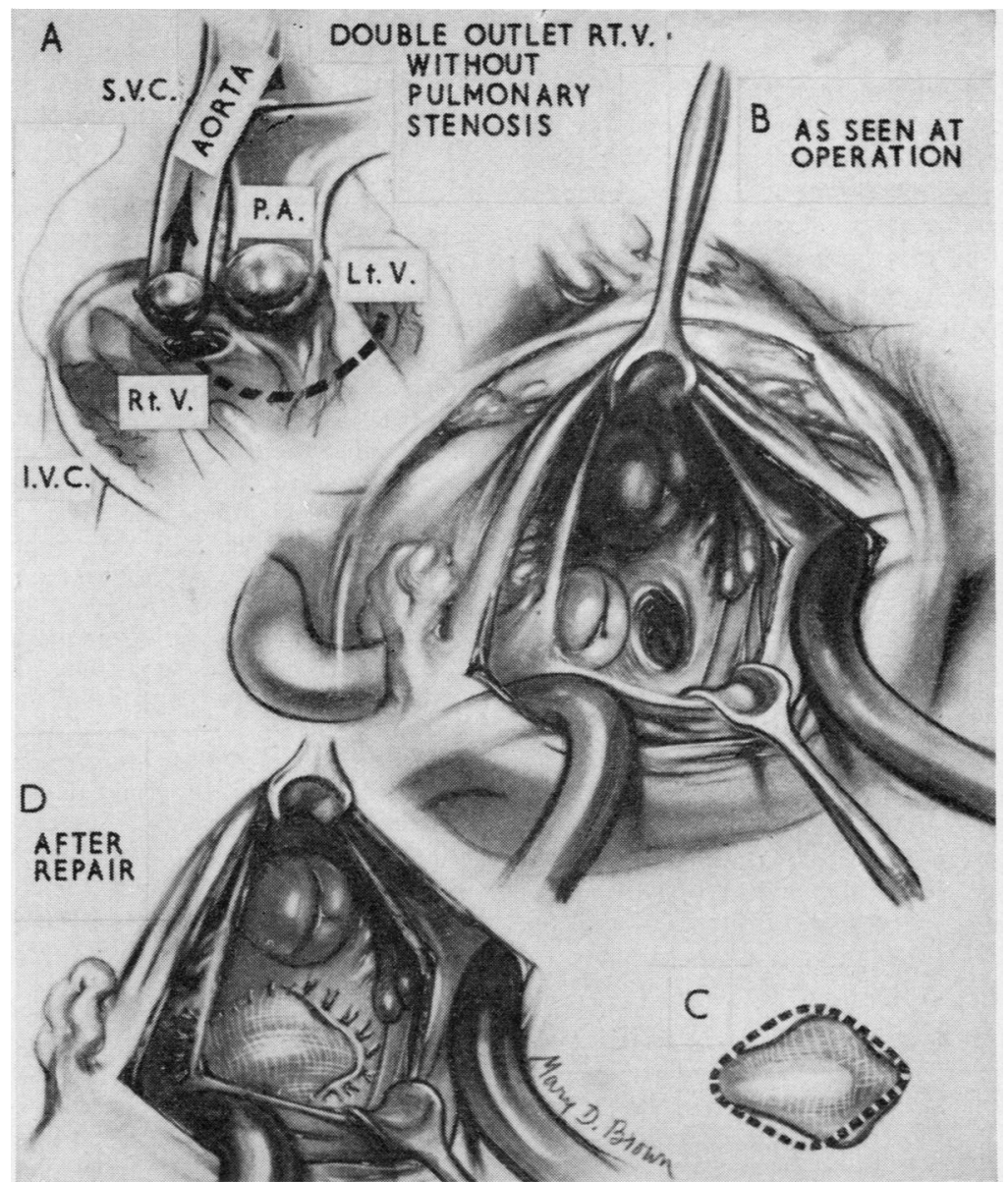

FIG. 3. Artist's view of surgical correction of a double-outlet right ventricle. (A) Diagrammatic representation of the pathology. (B) Surgical exposure of the right ventricle through an incision in the right atrium and retraction of the tricuspid valve; the pulmonic and aortic valves are seen and, close to the latter, the ventricular septal defect. $(C)$ The diamond-shaped Tefion prosthesis takes a curved form if sutured inside the heart. (D) The patch covering the V.S.D. and the aortic valve is like a curved channel through which the left ventricular blood is directed into the aorta and completely separated from the right ventricle.

$30 \times 20 \mathrm{~mm}$., located below the crista supraventricularis, was separated from the aortic annulus at a distance of $25 \mathrm{~mm}$. by a muscular ridge.

The surgical correction was carried out as shown in Figure 3. A diamond-shaped Teflon felt prosthesis was sutured in place in such a way as to construct a curved channel connecting the margins of the defect in the ventricular septum with the aortic annulus. The tricuspid leaflet was sutured back and the right atrium was closed. The whole procedure was carried out with the heart beating. The pressure in the pulmonary artery before repair was $90 / 50 \mathrm{~mm}$. $\mathrm{Hg}$ and that in the radial artery $90 / 55 \mathrm{~mm}$. $\mathrm{Hg}$. At the end of the procedure the pressure in the pulmonary artery dropped to $50 / 32 \mathrm{~mm}$. $\mathrm{Hg}$ with a systemic pressure of $82 / 45 \mathrm{~mm}$. Hg. Tracheostomy and intermittent positive pressure respiration was instituted following closure of the chest and was maintained for six days. The child made an uneventful recovery except for mild right heart failure which necessitated digitalization and small doses of diuretics in the first few post-operative days.

Comment Clinically, this child presented as a large ventricular septal defect and the diagnosis of a double-outlet right ventricle was not suspected 
because an angiocardiogram had not been performed.

We have also changed our policy with regard to doing a two-stage operation. Experience has shown that in patients with large ventricular septal defects and an associated patent ductus arteriosus there is little benefit from closing the ductus. It is best to close the ductus inside the pericardium immediately prior to establishing extracorporeal circulation (Kirklin and Silver, 1958 ; McGoon, 1964).

CASE 2 A 12-year-old boy was admitted to hospital in October 1964 for repeated pulmonary infections, fatigue, and dyspnoea on exertion. Clinical examination revealed an acyanotic patient with a precordial bulge and a systolic thrill and murmur characteristic of a ventricular septal defect. The second sound in the pulmonary area was accentuated. Femoral pulses were impalpable. The blood pressure in the right arm was $140 / 90 \mathrm{~mm} . \mathrm{Hg}$ and in the left $120 / 90 \mathrm{~mm}$. $\mathrm{Hg}$. The chest radiograph showed rib notching and marked cardiomegaly. The right ventricle was enlarged as well as the left ventricle and the pulmonary artery. There was also a considerable increase in the pulmonary vascular markings. Electrocardiograms demonstrated a mean electrical axis at about $+30^{\circ}$ and right and left ventricular hypertrophy. Cardiac catheterization was performed (Table III) and the

\section{T A B L E I I I}

CASE 2. CATHETERIZATION DATA, 30 OCTOBER 1964

\begin{tabular}{|c|c|}
\hline Oxygen Saturation $(\%)$ & Pressure $(\mathrm{mm} . \mathrm{Hg})$ \\
\hline $\begin{array}{l}\text { Inferior vena cava } 71 \\
\text { Superior vena cava } 60 \\
\text { Radial artery } 67 \\
\text { Right ventricle inflow tract } 72 \\
\text { Right ventricle outflow tract } 82 \\
\text { Aorta } 98 \\
\text { Left ventricle } 99\end{array}$ & $\begin{array}{l}\text { Right ventricle } 115 / 16 \\
\text { Pulmonary artery } 105 / 35 \\
\text { Aortic arch } 138 / 95 \\
\text { Left ventricle } 165 / 15\end{array}$ \\
\hline
\end{tabular}

following diagnosis was made: ventricular septal defect with pulmonary hypertension and a large leftto-right shunt associated with mild subvalvar aortic stenosis and coarctation of the aorta. It was decided to do a one-stage operation because of perfusion difficulties in the presence of coarctation and haemodynamic disturbances associated with pulmonary hypertension and subaortic stenosis.

At operation on 15 November 1964, through a lateral incision in the fourth intercostal space, a short coarctation at the usual site $(2 \mathrm{~mm}$. internal diameter) was resected. The position of the child on the operating table was then changed and the incision was enlarged across the sternum in the fifth right interspace. On opening the pericardium a small aorta arising to the right side of a greatly enlarged pulmonary artery was seen, suggesting that a type of double-outlet right ventricle might be present.
Under total body perfusion the right ventricle was approached through the right atrium by mobilizing the septal leaflet to the tricuspid valve. This gave an excellent view of the interior of the right ventricle and established the diagnosis of double-outlet right ventricle type 1.

The ventricular septal defect was located below the crista supraventricularis and approximately $20 \mathrm{~mm}$. away from the aortic annulus. The diameter of the defect measured about 15 to $18 \mathrm{~mm}$. and, being considered too small to support the systemic flow, it was enlarged to the size of the aortic annulus. A diamond-shaped Teflon prosthesis was then used to construct a channel between the left ventricle and the aorta. The tricuspid leaflet was resutured and the ? atrium was closed. The operation was performed without closs-clamping the aorta. Pressure measurements revealed the following figures. Before operation: right ventricle, $95 / 8 \mathrm{~mm}$. $\mathrm{Hg}$; pulmonary trunk. $90 / 30 \mathrm{~mm} . \mathrm{Hg}$; left ventricle, $132 / 14 \mathrm{~mm} . \mathrm{Hg}$ : radial $\rightarrow$ artery, $100 / 80 \mathrm{~mm}$. Hg. After repair: right ventricle. $\subseteq$ $42 / 3 \mathrm{~mm}$. Hg ; pulmonary trunk $40 / 22 \mathrm{~mm}$. Hg; left $\rightleftharpoons$ ventricle, $110 / 5 \mathrm{~mm}$. $\mathrm{Hg}$; radial artery, $110 / 75 \mathrm{~mm}$. $\vec{\bullet}$ $\mathrm{Hg}$.

Controlled respiration was maintained through a tracheostomy tube for four days. The patient was digitalized and received diuretics for three weeks following surgery. Eight months after the operation the child was symptom-free with good and equal pulses in the arms and legs. A systolic murmur grade $\mathbb{D}$ 1 to $2 / 6$ was audible over the left sternal border in the third interspace.

The electrocardiogram had not changed. The chest radiograph revealed a somewhat smaller cardiac shadow with fewer pulmonary vascular markings than before surgery.

Comment This patient did not show any specific signs to establish the correct diagnosis before the operation. The impression of subaortic stenosis 3 . was given by the pressure gradient across the 8 ventricular septal defect which was situated below the aortic annulus. A retrograde aortic catheter 0 entered the left ventricle across the outflow tract of the right ventricle without this being realized.

\section{DISCUSSION}

These two cases and other published reports show that a correct diagnosis of double-outlet right $\vec{\sigma}$ ventricle cannot easily be made on clinical grounds 0 alone. The physical signs and electrocardiographic $\underset{\mathbb{D}}{\stackrel{C}{ }}$ and radiological findings may be indistinguishable $\stackrel{\mathcal{D}}{\rightarrow}$ from those of a ventricular septal defect with 0 severe pulmonary hypertension and a left-to-right $\vec{O}$ shunt. Failure to recognize the true nature of the $\stackrel{\mathbb{D}}{\mathbb{D}}$ anomaly, even at open-heart operation, has led to $\mathbb{\mathbb { D }}$ closure of the ventricular septal defect with fatal results (Engle, Holswade, Campbell, and Gold- 
berg, 1960 ; Stevenson, Reid, Welsh, and Barclay, 1961 ; Redo et al., 1963).

The following points may help to establish the correct diagnosis.

ELECTROCARDIOGRAM Neufeld et al. (1961), in studying a group of patients with double-outlet right ventricle without pulmonary stenosis, found that the PR interval was greatly or slightly prolonged.

Their most important electrocardiographic finding was that the mean electrical axis of the QRS complex lay between $-30^{\circ}$ and $-170^{\circ}$ and the frontal QRS vector described a counterclockwise loop situated mainly above the iso-electric line. This resembles closely the findings in any form of atrioventricularis communis (Toscano-Barbosa, Brandenburg, and Burchell, 1956). Although this type of tracing might suggest the diagnosis of double-outlet right ventricle, it is by no means pathognomonic, since similar electrocardiographic patterns have been found in approximately $15 \%$ of cases having a simple ventricular septal defect (Keith, Rowe, and Vlad, 1958 ; Char, Adams, and Anderson, 1959 ; Toscano-Barbosa and DuShane, 1959).

It is noteworthy that the electrocardiograms in our two cases, as well as in other cases reported (McGoon, 1961 ; Engle, Steinberg, Lukas, and Goldberg, 1963 ; Hollman, personal communication), did not show these changes.

Nevertheless, we still believe that an electrocardiogram of this type should arouse suspicion of a complicated ventricular septal defect and demand further investigations.

RADIOLOGICAL APPEARANCES None of the authors we have consulted has found the conventional radiograph to be of diagnostic help in distinguishing a ventricular septal defect with pulmonary hypertension from a double-outlet right ventricle.

ANGIOCARDIOGRAPHIC FINDINGS Angiocardiography is essential to the pre-operative diagnosis. Carey and Edwards (1965) described the following findings in type 1 of this condition:

(a) Simultaneous and almost equal opacification of the aorta and pulmonary artery from contrast injection in the right ventricle.

(b) A ventricular septal defect located below the crista supraventricularis.

(c) The aortic and pulmonary valves at or nearly at the same level.

(d) Transposition of the aorta of a variable degree. In the lateral view the ascending aorta is usually superimposed on the posterior one-half or two-thirds of the proximal segment of the pulmonary artery and is located anteriorly even near the valve. In the frontal view the ascending aorta appears foreshortened with less curvature than normal.

(e) The most important angiocardiographic finding is a 'tongue-like' filling defect seen in the frontal view at the base of the right ventricle. This represents the $x$-ray projection of the crista supraventricularis which separates the outflow tract of the right ventricle into two streams, one going into the pulmonary artery and the other into the aorta. This appearance, when clearly outlined, seems to distinguish absolutely the double-outlet right ventricle syndrome.

CARDIAC CATHETERIZATION Catheterization might be expected to give the diagnosis, but in fact the pressure recordings and blood oxygen saturation may be indistinguishable from those of a simple ventricular septal defect with severe pulmonary hypertension and a large left-to-right shunt. This is particularly true in cases of double-outlet right ventricle with little mixing of venous and arterial blood in the right ventricle. Under these conditions a streaming effect takes place in the right ventricle so that the mixed venous blood is directed into the pulmonary artery and the arterialized blood mainly into the aorta. When this occurs the oxygen saturation in the pulmonary artery is higher than in the right atrium but significantly less than that of the systemic arterial blood. In such patients, as in our case, the diagnosis cannot be made by cardiac catheterization alone. If, on the other hand, an extremely large left-to-right shunt at ventricular level is found and the oxygen saturation in the pulmonary artery approaches or equals that in the aorta, indicating that relatively complete mixing of venous and arterial blood has oscurred in the right ventricle, the presence of double-outlet right ventricle or a single ventricle needs to be considered. Neufeld et al. (1961) described a technique, using two catheters, by which the diagnosis of a double-outlet right ventricle can be established by showing the position of the aorta and pulmonary artery relative to each other.

In rare instances the oxygen saturation in the aorta is reduced because of severe pulmonary vascular disease or acquired pulmonary stenosis while the left-to-right shunt is shown to be still present by the rise in oxygen saturation of the blood in the pulmonary artery. This helps to differentiate the type 1 double-outlet right 
ventricle from the Eisenmenger complex and from Fallot's tetralogy but not from the type 2 a doubleoutlet right ventricle (Taussig Bing complex).

Pressure measurements almost always disclose a striking similarity between the right ventricle and a systemic artery because the aorta originates from this chamber. The systolic pressure in the pulmonary artery approaches closely the right ventricular systolic pressure.

In the presence of clinical signs of ventricular septal defect and equal pressures in the right ventricle and the aorta the possibility of a doubleoutlet right ventricle should always be considered and further investigations performed.

If hypothetically the actual pulmonary flow, as measured directly with an electromagnetic blood flow-meter, is essentially the same in a number of patients and all the other data are the same, there could be a large variation in oxygen saturation in the pulmonary artery due to a different mixing in the outflow tract of the right ventricle.

Therefore, calculated flow and resistance, which depend mainly on blood oxygen saturation data, are not accurate figures in such cases and consequently not of prognostic significance.

We consider that the haemodynamic features in double-outlet right ventricle depend largely on the anatomical arrangement inside the heart which alters during the cardiac cycle. These include the size and position of the ventricular septal defect, the relationship of the defect to the aortic and pulmonic valves, and especially the position and shape of the crista supraventricularis.

The diagnosis of this rare condition, even difficult, may be established before operation by proper use and careful interpretation of all the clinical and laboratory data and particularly by the angiocardiographic findings. However, there will still be situations in which the erroneous diagnosis of a ventricular septal defect is made.

At operation the suspicion of a more complicated condition arises even before opening the heart when the aorta is seen to lie to the right of the pulmonary artery and parallel to it, especially if the diameter of the aorta is smaller than normal and the pulmonary artery is very much enlarged.

Looking as well as working through the right atrium has in our experience many advantages. First, the relationship between essential structures inside the right ventricle is not disarranged and a better assessment of the complex functional anatomy is achieved. A longitudinal incision in the wall of the right ventricle will almost always, by tractions exerted on the free edges, modify the position and the relationship between the ventricular septal defect and the aortic annulus.

Secondly, from the experience gained by closure of uncomplicated ventricular septal defects through the right atrium, it is technically easier to perform the repair through this approach.

Finally, and perhaps most important, the right atrial approach does not interfere with aberrant coronary arteries (Engle et al., 1963 ; Redo et al., 1963) nor with the function of the right ventricle in the immediate post-operative period, and, in our opinion, it is certainly the correct method in these patients with severe pulmonary hypertension.

The surgical concepts and the technique itself for complete repair of this anomaly have been described in detail previously by McGoon (1961) and by Kirklin et al. (1964), so that little comment is required. A diamond-shaped Teflon prosthesis is made and sutured in such a way as to construct a curved channel to carry the blood from the left ventricle to the aorta. This channel must be of such a size that it does not impede emptying of the left ventricle nor obstruct the outflow tract of the right ventricle.

The ventricular septal defect must be enlarged if necessary so that it equals the size of the aortic annulus. Care needs to be taken not to damage the bundle of His or the aortic valve.

We have found that the approach through the right atrium gives a better view for this repair than does a ventricular incision, and we consider it to be the method of choice for the repair of this defect.

We thank Dr. P. G. F. Nixon, who carried out the cardiac catheterization in one case, and Dr. Frederic Jackson for review of the manuscript. We are grateful to Miss Mary Brewn for drawing Figure 3.

\section{REFERENCES}

Abbott, M. E. S. (1936). Atlas of Congenital Cardiac Disease. American Heart Assoclation, New York.

Carey, L. S., and Edwards, J. E. (1965). Roentgenographic features in cases with origin of both great vessels from the right ventricle
without pulmonary stenosis. Amer. J. Roentgenol., 93, 269.

Char, F., Adams, P., Jr., and Anderson, R. C. (1959). Electrocardio- $\mathrm{N}$ graphic findings in one hundred verified cases of ventricular $\omega$ septal defect. Amer. J. Dis. Child., 97, 48.

Edwards, J. E. (1960). Congenital malformations of the heart and great vessels. In Pathology of the Heart. Ed. Gould, S. E., 2nd ed., pp. 260-496. Thomas, Springfield, Illinois.

Engle, Mary A., Holswade, G. R., Campbell, W. G., and Goldberg, $\mathscr{D}$ H. P. (1960). Ventricular septal defect with transposition of aorta masquerading as acyanotic ventricular septal defect. Abstracts of the 33rd Scientific Session of American Heart Abstracts of the 33rd Scientific Session of American Heart

Steinberg, I., Lukas, D. S., and Goldberg, H. P. (1963). Acyano- $\vec{D}$ tic ventricular septal defect with both great vessels from the right $\frac{\Omega}{T}$ ventricle. Amer. Heart J., 66, 755.

Ingham, D. W., and Willius, F. A. (1938). Congenital transposition of the great arterial trunks. Ibid., 15, 482 .

Keith, J. D., Rowe, R. D., and Vlad, P. (1958). Heart Disease in Infancy and Childhood. Macmillan, New York. 
Kirklin, J. W., Harp, R. A., and McGoon, D. C. (1964). Surgical treatment of origin of both vessels from right ventricle, including cases of pulmonary stenosis. J.thorac. cardiovass. Surg., 48, 1026.

- and Silver, A. W. (1958). Technic of exposing the ductus arteriosus prior to establishing extracorporeal circulation. Proc. Mayo Clin., 33, 423.

McGoon, D. C. (1961). Origin of both great vessels from the right ventricle. Surg. Clin. N. Amer., 41, 1113.

- (1964). Closure of patent ductus during open-heart surgery. J. thorac. cardiovasc. Surg., 48, 456.

Morgan, J., Pitman, R., Goodwin, J. F., Steiner, R. E., and Hollman, A. (1962). Anomalies of the aorta and pulmonary arteries complicating ventricular septal defect. Brit. Heart J., 24, 279.

Neufeld, H. N., DuShane, J. W., Wood, E. H., Kirklin, J. W., and Edwards, J. E. (1961). Origin of both great vessels from the right ventricle. I. Without pulmonary stenosis. Circulation, 23, 399.

Lucas, R. V., Jr., Lester, R. G., Adams, P., Jr., Anderson, R. C., and Edwards, J. E. (1962). Origin of both great vessels from the right ventricle without pulmonary stenosis. Brit. Heart J., 24, 393.
Redo, S. F., Engle, Mary A., Holswade, G. R., and Goldberg, H. P. (1963). Operative correction of ventricular septal defect with origin of both great vessels from the right ventricle. J. thorac. cardiovasc. Surg., 45, 526.

Rokitansky, K. (1875). Die Defecte der Scheidewände des Herzens: Pathologisch-anatomische Abhandlung. Braümuller, Vienna.

Saphir, O., and Lev, M. (1941). The tetralogy of Eisenmenger. Amer. Heart J., 21, 31

Stevenson, J. G., Reid, J. M., Welsh, T. M., and Barclay, R. S. (1961). The double outlet right ventricle syndrome. Scot. med. J., 6, 555

Toscano-Barbosa, E., Brandenburg, R. O., and Burchell, H. B. (1956). Electrocardiographic studies of cases with intracardiac malformations of the atrioventricular canal. Proc. Mayo Clin., 31, 513.

- and DuShane, J. W. (1959). Ventricular septal defect: correlation of electrocardiographic and hemodynamic findings in 60 proved cases. Amer. J. Cardiol., 3, 721.

Witham, A. C. (1957). Double outlet right ventricle: A partial transposition complex. Amer. Heart J., 53, 928. 